\title{
NEW DEVELOPMENTS IN PESTICIDES FOR IPM IN AFRICA, WITH SPECIAL REFERENCE TO COTTON PESTS
}

\author{
BURKHARD SECHSER \\ CIBA-GEIGY Lid., Agricultural Division, Basle, Switzerland
}

(Received 17 July 1989)

\begin{abstract}
There is a large knowledge base available worldwide for growing many crops according to the principles of integrated pest management (IPM). CIBA-GEIGY is active in much IPM related research. Several biological control projects are being carried out at present and include studies of Trichogramma minutum against the spruce budworm in Canada; Encarsia sp. against glasshouse white-flies in Spain; the fungus Beauveria brongniartii against cockchafers in fruit gardens and forests of Switzerland and Italy; and the protozoan (Nosema) preparations against the African desert locust. In cotton, CIBA-GEIGY is concentrating on testing pesticides for the selectivity of beneficial arthropods under practical field conditions.

Some of the most important pests in cotton, rice and vegetables are monitored regularly for the occurrence of resistance, and strategies are being developed to overcome it. A computer model has been developed for American cotton, which is now under practical evaluation and which should allow for appropriate treatment decisions based on plant phenology and regular pest scouting.

General recommendations are given as to the implementation of IPM programmes in cotton, which are based on methodologically sound monitoring of cotton arthropods, establishment of economic thresholds, use of selective compounds or the selective use of broad spectrum pesticides, rotation of pesticides of different chemical classes to avoid the build-up of resistance, and a strengthened search for biological control alternatives such as more potent strains of Bacillus thuringiensis.
\end{abstract}

Key Words: Trichogramma minutum, Encarsia sp., Beauveria brongniartii, Nosema, Bacillus thuringiensis, integrated pest management, plant phenology, pest scouting

Résumé-Il y a certaines connaissances de base à travers le monde pour la production de plusieurs cultures suivant les principes le la gestion intégrée des ravageurs. CIBA-GEIGY s'occupe de nombreux programmes de recherche concernant la gestion intégrée des ravageurs. Plusieurs projets de lutte biologique sont en cours déxécution. Ces projets comprennent: Trichogramma minutum contre la tordeuse des bourgeons au Canada, Encarsia sp. contre les mouches blanches en Espagne, Beauvaria brongniartii contre les hannetons des arbres fruitiers et des forêts en Suisse et en Italie et le protozoaire Nosema contre les criquets en Afrique. Pour le coton CIBA-GEIGY est en train de tester sur le terrain des insecticides quant à la selectivité envers des arthropodes. Quelques ravageurs très importants du coton, du riz et des legumes sont etudiés quant à leur resistance contre les insecticides afin de developper des stratégies pour les combattre. Un modèle fut developpé pour le coton americain et le résultat de cette recherche aura un rôle à jouer dans les décisions pour les traitements appropriés en se basant sur la phénology des plantes et le contrôle visuel périodique des ravageurs. Des recommendations générales sont données pour l'utilisation des programmes de gestion integée des ravageurs basés sur des methodes saines pour l'environnement et surtout renforcer la recherche des agents de lutte biologique tels que Bacillus thuringiensis en souches plus efficaces.

Mots Clefs: Trichogramma minutum, Encarsia sp., Beauvaria brongniartii, Nosema, Bacillus thuringiensis, gestion integrée des ravageurs, phenologie, contrôle visuel 


\section{INTRODUCTION}

Modern terminology dictates that we use the term "pest management" rather than pest control, as was the case for so many years. This emphasizes the management of pests rather than the control, per se, which has carried the connotation of insecticidal control since the emergence of the synthetic organic insecticide era in the late 1940s. The reason for the distinction here is to point out the multiplecomponent approach that is available to manage our cotton pests, insecticides comprising only one of these components.

During the growing season, however, insecticidal control is the major component with which man can most easily manipulate to prevent excessive damage by important cotton pests. The key to an effective pest management programme is the correct use of these insecticides, i.e., when economically justified, at the correct dose and in a safe manner. Herbicides and fungicides are less important components in the cotton crop management.

The use of chemical insecticides is and in the foresecable future will be our most important cotton insect control tactic. Our present arsenal of insecticides is tremendous as compared to earlier periods of time. The advantages and disadvantages of chemical control tactics are widely known and accepted. Our present insecticides are extremely effective (i.e., high efficacy masks many mistakes and misuses), easy to use (i.e., only limited skill and effort required), and rather environmentally safe as compared to compounds previously used on cotton.

If too much insecticide of the incorrect kind is used, i.e. when unnecessary, no benefit is realized in terms of increased yields or improved quality, but excessive use may prove detrimental, above and beyond the increased cost of producing the crop. Some of these detrimental side effects include the development of resistance to pesticides, destruction of beneficial species and build-up of harmful residues.

The consequence of too little use of insecticides may be the loss of yield and/or quality of the crop. This puts the grower in a dilemma of not knowing the most appropriate time to use an insecticide. In order to know this, one must utilize, to the fullest extent possible, the basic elements of insect pest management, cultural control, natural control, biology and ecology of both the pests and beneficial species, sampling, economic thresholds, selective insecticides or the selective use of broad-spectrum products. To combine all these elements into a sound control strategy is not easy to achieve for farmers in Africa.

\section{CONSTRAINTS TO THE IMPLEMENTATION OF IPM IN AFRICA}

\section{Availability of chemicals}

No reliable distribution system exists in many countries which could guarantee the farmer having the product when he needs it.

\section{Information and training}

A farmer should know what pests are present in his crops, whether the pest level is potentially damaging and then he must know to apply the insecticides effectively and safely. Education and training is a task of the local extension service with advice by the chemical companies, but is not yet adequate in all parts of Africa.

\section{Cost-benefit ratio}

Prices for agricultural goods are often low, therefore it must be possible to demonstrate a clear consistent economic benefit from using the insecticide.

\section{Safety and environment}

Insecticides for developing countries need to be simple to use (e.g. exact timing is more difficult with insect growth regulators) and non-hazardous to the user and the environment (e.g. chlorinated hydrocarbons are in general less suitable for an IPM system).

\section{Durability}

The efficacy of an insecticide may be lost if the pest species adapts and becomes less sensitive to the chemical. The most critical pests are those which have a very short generation time and produce high numbers of individuals and generations per season.

Insecticides are pest management tools which can be flexibly integrated into an IPM programme, but their safe and effective use requires a certain degree of training. Companies are very much concerned that their products are used properly, according to recommendations. It is clear that the safe and effective use of insecticides requires cooperation at the local level between company and government extension staff. 


\section{INCENTIVES FOR THE IMPLEMENTATION} OF IPM IN COTTON

\section{Resistance management}

Experience in the past has demonstrated clearly that the development of resistance in a pest population has been the most stimulating motivation to adopt some kind of an IPM system. Simple strategies to avoid or manage insecticide resistance have been developed and proven in wide-scale testing. The general strategies are:

(1) Limit the duration of use/rotate with insecticides of adifferent chemical class: Insecticides of a chemical class should be applied to not more than one generation of the pest during the season.

(2) Use of mixtures: A mixture of two insecticide components with different modes-ofaction exerts a different selection pressure on the pest population.

The most recent example in cotton has been the appearance of resistance to pyrethroids in the AfroAsian bollworm species, Heliothis armigera, in some parts of Australia. An insecticide use strategy was developed, the basis of which is to restrict the use of pyrethroids to a maximum of three sprays against only one bollworm generation (of the four or five generations that can occur in a season). If the use of pyrethroid sprays is discontinued after this period, any pyrethroid-resistant survivors can be controlled by alternative chemicals. The strategy is set out for the season in three time stages: early, mid-season and late. Table 1 lists the names of the recommended

Table 1. Insecticide treatment scheme in Australian cotton

Early Mid-season Late

\begin{tabular}{|c|c|c|}
\hline Endosulfan & Endosulfan & Profenofos \\
\hline Profenofos & Profenofos & Sulprofos \\
\hline Sulprofos & Sulprofos & Thiodicarb \\
\hline Thiodicarb & Thiodicarb & Acephate \\
\hline Acephate & Acephate & Methomyl \\
\hline Methomyl & $\begin{array}{l}\text { Methomyl } \\
\text { Parathion } \\
\text { Pyrethroid }\end{array}$ & Parathion \\
\hline
\end{tabular}

\footnotetext{
No more than three No pyrethroids No pyrethroids pyrethroid sprays and endosulfan in this stage
}

insecticides for the three stages. Monitoring of resistance levels since then has shown that the strategy is sound. Resistance levels rose when pyrethroids were used but fell significantly when they were withheld. Given sustained grower support, the pyrethroids (and for that matter, all the other Heliothis insecticides) should continue to work well for many years to come.

A similar strategy has been followed up already for several decades by the Egyptian authorities in their battle to control the pink bollworm, Pectinophora gossypiella and the cotton leafworm Spodoptera littoralis. In spite of the rotation of many different chemicals, some of them became ineffective over the years, but the situation never got as desperate as in Australia at the early stage of the pyrethroid use.

Continued efforts are necessary along this line since reports from the USA indicate a decreasing susceptibility to pyrethroids of the New World bollworms, Heliothis zea and $H$. virescens, and resistance of other cotton leafworms in both Americas.

The build-up of resistance can be further delayed by the properly timed application of insecticides based on sound economic thresholds. In order to establish economic thresholds, adequate sampling techniques must be developed and used. Sampling for this purpose is generally much more exhaustive than that used in a scouting programme on which control decisions are made. Because of the difficulty in establishing sound economic thresholds, i.e. time and effort required, they are for the most part totally inadequate in cotton. The majority are not derived from experimental data, but mostly from arbitrary selection and traditional practices. This fact should not be a deterrent to the use of the ones we currently have. In any event, this is a far better method of controlling cotton pests than that used in earlier days of calendar-scheduled applications.

\section{Conservation of beneficials}

The control success of insecticides can be further increased by using more selective compounds to save the natural enemies of the pests. This requires appropriate testing methods to evaluate the short and long term impact of chemical treatments. The chemists can contribute in this respect by concentrating their synthesis efforts on promising computer models as this is the case with benzoylureas. 


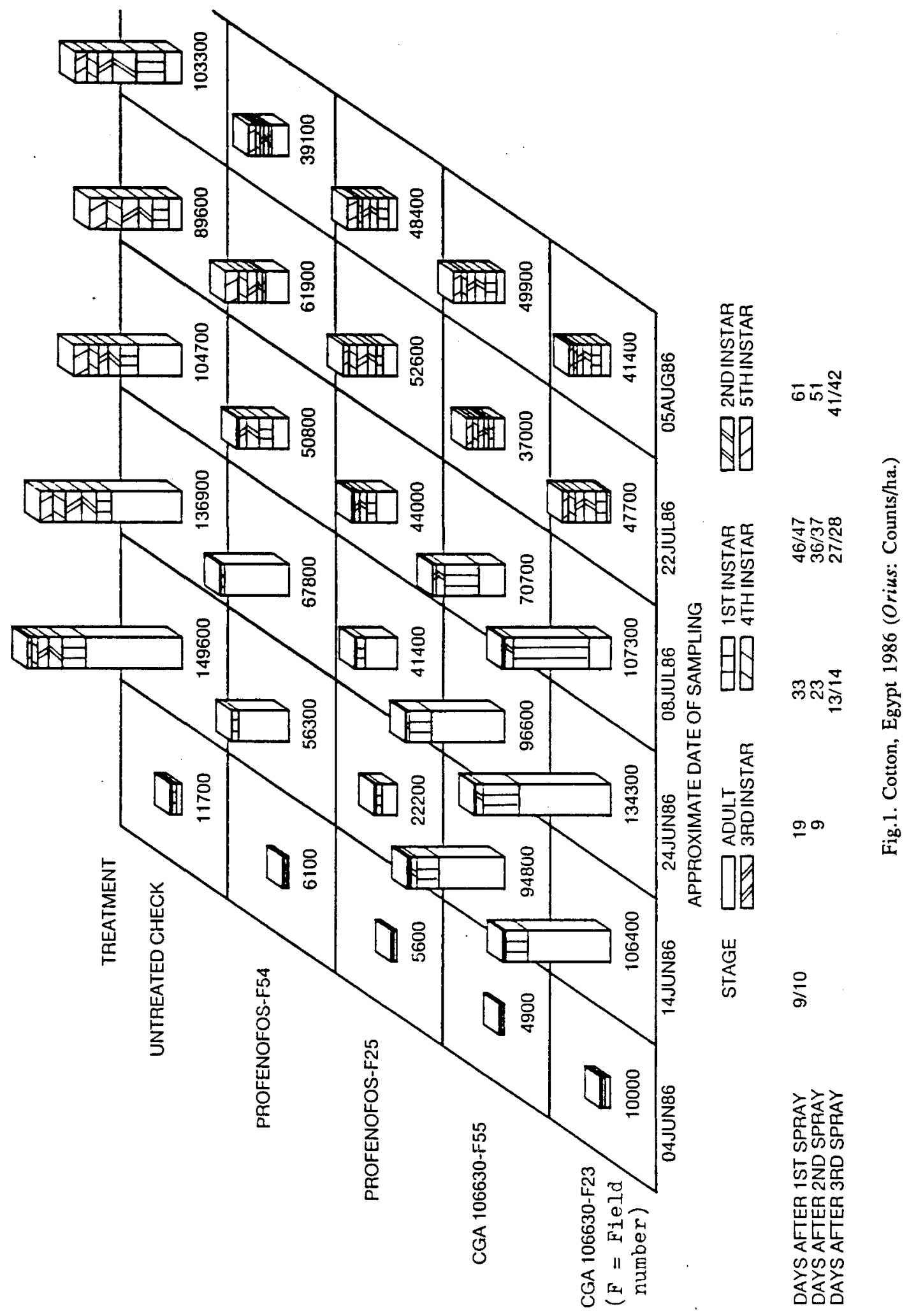




\section{Profit to growers}

IPM to date has addressed largely the question of farmers' profits: The question of how to increase yield through IPM has largely been ignored, probably because IPM was born out of European and North American environments of surplus and setaside. For African farmers, our attention must concentrate on ways to achieve maximum yields and IPM profits by increasing the efficacy of control measures and decreasing their cost. Much more research effort is required to develop effective lowcost pest control methodologies. Finally these efforts should result in a higher profit to the IPM practitioner.

\section{Environment protection}

Application of pesticides according to economic threshold levels normally would result in a reduced number of sprays. Therefore the total pesticide load of the environment should decrease in the long term.

\section{WHAT CAN CIBA-GEIGY OFFER FOR AN IPM SYSTEM IN COTTON?}

Chemical companies have seen their main role in IPM in the past as synthesizing and developing safe and selective pesticides. A commitment to IPM was considered for a long time as a risk of reducing market size and loss of market shares. However, some recent developments signal a change in the companies' policies:

(1) Commitment to an internal quality concept, i.e. providing the end users with a maximum of information on how to manage their pests and pesticides in the best way. Beyond this on behalf of CIBA-GEIGY, the following points can be made:

(i) Commitment to the FAO Code of Conduct

(ii) Evaluation of possibilities to include broad-spectrum insecticides in IPM systems in the most compatible way

(iii) Studies of resistance management systems as part of IPM to prolong the life of valuable chemistry

(iv) Education of users on correct application of insecticides.

Several IPM-relevant activities have been launched by CIBA-GEIGY over the past decade or more in selected crops. Test results with insecticides on the crops mentioned under the following items (deciduous fruit, rice, citrus) are also a valuable source of information for cotton since these products are also often used in this crop.
(2) Selectivity tests on deciduous fruit beneficials have the longest history. This crop has several groups of very efficient natural enemies. Tests are applied routinely to measure the short and long term impact of insecticides on these beneficials.

(3) In rice in Indonesia tests over several years aim to testing economic thresholds and comparing their performance with other insecticide use strategies and farmers' practices. Preliminary efforts are being made to extend techniques for pest identification and sampling to rice farmers.

(4) A scalicide is being tested on citrus to get more detailed information on its impact on specific and general scale beneficials.

(5) Cotton has seen many IPM-relevant activities:

(i) Insecticides are tested for their selectivity on cotton beneficials at our Egyptian research station. A proper method has been developed within the company which offers considerable advantages over existing ones. The principle of the new method is to shake whole cotton plants from two parallel rows over a plastic sheet in between the rows. The dislodged arthropods are sampled with a vacuum cleaner and transfered to the laboratory for counting. The method allows the collection of rather large samples in a short period of time, the evaluation of very small developmental stages and of morphogenetic aberrations of the type caused by insect growth regulators. Sampling at regular intervals also allows rating of the speed and degree of reimmigration of beneficials into treated fields and the recovery of the beneficials' population. An example of a testing result is presented in Fig. 1, where Orius nymphs start normal development 13 days after a third treatment with Profenofos, while a new type of an acaricide/insecticide with the code number CGA 106'630 (diafenthiuron) proved to be completely safe to this predator.

(ii) A whole range of cotton pests have been regularly monitored for resistance $(R)$ by a companyoperated working group.

The cotton leafworm, Spodoptera littoralis, is one of these species. This pest has a long history of exposure to pesticides and consequent $R$ development in Egypt. By following a strict regime of spray rounds with insecticides of varying chemical type, the Egyptians established a successful partial IPM system for Spodoptera control. The R-factor varies from one product class to the other, but on the whole, the R situation in Egypt in Spodoptera as well as Pectinophora seems to be reasonably stable.

(iii) Amongst the natural control agents suited for IPM, Bacillus thuringiensis (B.t.) is a favourite 
due to the high selectivity. Limiting factors in the past have been:

(a) Its rather narrow spectrum of activity, and

(b) Its inherent weakness against the most important chewing insects in cotton, Heliothis and Spodoptera.

CIBA-GEIGY tries to overcome this by creating novel strains. A first strain with increased activity against both pests was and is being field-tested in Egypt.

(iv) Computer modelling and the use of expert systems has become an issue in the USA in an attempt to simulate the cotton plant growth and external inputs (weather, irrigation, cultivation, fertilizers, pests, insecticides, beneficials etc.). Based on existing models, a CIBA-GEIGY cotton model (GOSINS) has been developed and is now being tested in Mississippi under practical conditions. The objective of the USA modelling project has been to use it as a research tool for insect control (planning and interpretation of field trials).

(6) CIBA-GEIGY is actively involved in the development of purely biological control methods: The basic knowledge, which we are able to acquire in these projects, may perhaps be applied one day also usefully in similar projects in Africa.

\section{PROPOSALS FOR IPM RESEARCH AND EXTENSION PILOT PROJECT IN COTTON}

Cotton used to be a favourite crop for IPMoriented activities in the past. With the appearance of the potent pyrethroid insecticides these efforts decreased but may be reversed in the light of obvious or supposed signs of resistance/decreased susceptibility of some main chewing insects to this chemistry. Preventive research efforts are recommended to keep these and other cotton insecticides alive as part of a pest control strategy.

Cotton is cultivated on a large acreage in Africa. Insecticide resistance is a constant threat to all cotton growing countries and should be a stimulant for a reorientation in the control tactics. It is with these points in mind that the following proposal is made for IPM oriented programmes to be carried out in cooperation with international organizations in cotton, of which the primary objectives are:

Target (1) Basic research on IPM systems which increase yield as well as profit

Proposed actions. Support of research work in a representative location aimed at improvements in yield and profit through improved pest control, by:
(1) careful identification of key endemic pests

(2) careful identification of key predators

(3) design of low-cost control measures (cultural and / or chemical) against those endemic pests

(4) collection and retrieval of data from cotton

(5) investigate and verify the usefulness of the established collection methods

(6) investigate basic technical questions which are necessary to make use of the collected information for optimal management such as:

(a) optimal timing for the control of different pests

(b) effect of pests on the plants to determine threshold levels and / or their modification

(c) performance of control agents on pests/ beneficials

(d) effect of beneficials on pests

(e) effect of planting date on pest infestation

(7) development of simple forecasting models to help manage fields

(8) develop simulation models and expert systems to guide research for unsolved problems of cotton management.

Target (2) Improving cotton farmers' ability to recognize pests and beneficials

Proposed actions. Sponsoring displays with preserved insect specimens for better recognition.

Target (3) Training farmers to be able to assess the level of pests in their fields in relation to economic thresholds

Proposed actions. Development of simple counting devices and poster campaigns.

Target (4) Improving farmers' knowledge of how to use insecticides effectively and safely

Proposed actions and poster campaigns. Design of proper recommendations to accompany the IPM campaign, stressing:

(1) timing of the application when economic thresholds are reached

(2) choice of suitable insecticide

(3) correct dose and volume

(4) safe storage

(5) avoidance to spill spray liquids.

All the proposed actions should help in the development of optimal practices for integrated pest management in African cotton.

Acknowledgement-The author thanks Dr. W. Vorley for allowing the use of the target items from another project proposal in a slightly modified form. 